\title{
TUBERCULOSIS INFECTION CONTROL MEASURES AT HEALTH FACILITIES PROVIDING TUBERCULOSIS SERVICES IN NEPAL
}

\author{
Adhikari N', Bhattarai $\mathbf{R}^{1}$, Basnet R', Joshi LR \\ ${ }^{1}$ National Tuberculosis Center/Global Fund Program, Thimi, Bhaktapur
}

\begin{abstract}
Introduction: Globally there were an estimated 10.6 million new tuberculosis patients and 1.7 million deaths from TB in 2016. There is an evidence of tuberculosis transmission at health care settings where health care workers and patients come in contact with people having tuberculosis. This study aims to explore infection control measures at health facilities in terms of administrative, environmental and personal protective measures needed for infection control.
\end{abstract}

Methods: This is a cross-sectional study carried out at 79 health facilities across the country. The study continued for three months starting from January 2018 to March 2018. Trained enumerators from health sciences background collected the information using semi-structured questionnaire. Written consent was obtained prior interview.

Results: All the selected health facilities participated in the study. Around $44 \%$ of health facilities have infection prevention plan, but very few of them have budgeted for tuberculosis infection control activities. Less than one third of health facilities (24 out of $79 \mathrm{HFs}$ ) have provision to separate presumptive tuberculosis patients, however, only $50 \%$ ( $12 \mathrm{HFs}$ ) have turned such provision into action. Only $15 \mathrm{HFs}$ (38\%) out of $40 \mathrm{HFs}$ having N95 or FPP2 mask for health workers. Around half of the HFs (44\%, 35 out of 79) was found to have cross ventilation.

Conclusion: Tuberculosis infection plan needs to be developed and implemented by all the health facilities to strengthen administrative, managerial, and environmental and person protective measures of inaction control to minimize the risk of TB transmission at health facilities.

Key words: Infection control, infection prevention, tuberculosis, TB, Nepal

\section{INTRODUCTION}

Tuberculosis (TB) is one of the leading cause of death worldwide. 'Globally there were an estimated 10.6 million new TB patients and 1.7 million deaths from TB in 2016. ${ }^{2}$ Moreover it is a leading killer disease among HIV positive people accounting $40 \%$ of total death among HIV positive. ${ }^{3}$ Besides, the emergence of drug resistant forms of TB has threaten the TB prevention and treatment efforts. ${ }^{4}$

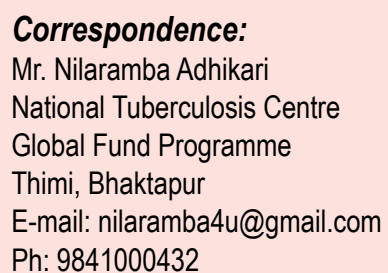

In Nepal, tuberculosis ranks among the top ten diseases causing morbidity and mortality. ${ }^{5} \mathrm{~TB}$ incidence is 152 per 100000 population. ${ }^{6}$ In 2016, National Tuberculosis program registered 32,056 TB cases, half $(53 \%)$ of them were new and relapsed pulmonary smear positive TB cases. National Tuberculosis Program provides TB diagnostics and treatment services free of cost to all TB patients across the country. ${ }^{7}$

There is an evidence of TB transmission in health care settings where health care workers and patients come in contact with people who have TB disease. ${ }^{8,9}$ Insufficient tuberculosis infection control (TB-IC) measures at the facility pose serious risk to health workers and other patients attending health facilities. ${ }^{10}$ Even, TB-IC is one of the WHO recommended 12 collaborative TB/HIV 
activities. ${ }^{11}$ The absence of TB-IC policy, guidelines and appropriate interventionsat health facility needs immediate attention to reduce the risk of TB transmission. Thus, this study aims to explore infection control measures at health facilities in terms of administrative, environmental and personal protective measures needed for infection control.

\section{METHODS}

This is a cross-sectional study carried out at health facilities providing TB diagnosis and treatment services. All the health facilities offering TB services (DOTS center, Microscopy center, Culture lab, DR center/sub center) were included in the sampling frame. This study continued for three months starting from January 2018 to March 2018.

Sample size for the study was determined based on the sampling manual for health facility surveys.${ }^{12} \mathrm{~A}$ total of $205 \mathrm{HFs}$ was initially planned to visit for assessment. However, due to budget and time constraints, only $79 \mathrm{HFs}$ (including 23 microscopy centers) from 8 districts (Morang, Khotang, Saptari, Sindhupalchowk, Tanahun, Rupandehi, Surkhet, Kailali) were selected for the study purpose. The cluster design adopted by Nepal Demographic and Health Surveys (NDHS) stratifies Nepal into three topographic zones (mountain, hill and Terai), five development regions. The same 15 subregional domain was planned to be used in this assessment. ${ }^{13}$ Due to study limitations, we could not follow aforementioned technique. Thus, we randomly selected districts from each province for this assessment. A proportionate allocation of service delivery sites was done to select microscopy and DOTS center from selected districts.

This assessment majorly focused on three dimensions of infection assessment i.e. Administrative, Environmental and Personal protective equipment. The required information was collected using semi-structured questionnaire. Questionnaire was developed based on WHO health facility assessment checklist, and $C D C$ TB-IC checklist. Similarly, a further consultation with the program and laboratory focal persons at National Tuberculosis Center (NTC) was done to contextualize the questionnaire in country's setting.

Trained enumerator collected information using face to face interview technique. Written consent was obtained from all the health workers prior the interview. A database was prepared in CSPRO 7 for data entry. Different checks (range checks, skip) were applied to maintain data quality. Data was further exported to STATA 14.0 for further analysis. Descriptive and exploratory data analysis (summary statistics, frequency distributions) was performed to assess the situation of tuberculosis infection control measures at the study sites.

\section{RESULTS}

All health facility participated $(100 \%)$ in this assessment. This section elaborats the situation of managerial, administrative, and environmental measures adopted by health facilities for the tuberculosis infection control (Table 1).

\section{Facility level managerial activities}

Out of 79 health facilities (HFs), less than half $(44 \%, 35 \mathrm{HFs})$ had a general infection prevention plan. Of those health facilities having infection prevention plan, only 24 health facilities had TB infection control (IC) plan included in their overall IC plan. Less than one third (28\%, $22 \mathrm{HFs})$ had a focal person for infection control. Only 9 service delivery sites were found to have IC committee.

\section{Administrative information of service delivery sites}

Majority of HFs ( $89 \%, 70$ out of $79 \mathrm{HFs}$ ) was found to screen patients for TB. However, less than one third $(30 \%, 24 \mathrm{HFs})$ had provision for separation of presumptive TB patients. Among them, majority ( $80 \%, 19$ out of $24 \mathrm{HFs}$ ) were found to separate presumptive TB patients. Around one third of HFs (34\%, $24 \mathrm{HFs}$ ) had provision of mask for suspected or TB patients, while 19\% (15 HFs) had provision of tissues for TB patients. Similarly, more than two third $(71 \%, 56 \mathrm{HFs})$ had dustbin to dispose used tissue as a part of respiratory hygiene practice. Nearly half of the HFs (48\%, 38 out of $79 \mathrm{HFs}$ ) had IEC materials on coughing etiquette. Among them, majority ( $90 \%$, 34 out of $38 \mathrm{HFs}$ ) had placed IEC material at visible place to all patients. Nearly all $\mathrm{HFs}$ replied to provide health education to all TB patients. Health worker focused on use of tissue/ handkerchief while coughing (38\%), followed by use of mask $(24 \%)$, use of hand while coughing 
$(20 \%)$ while providing health education. However, only $14 \%$ of health workers were screened for TB by the respective HFs. More than half ( $56 \%, 13$ out of 23) of the HFs had separate room for sputum sample collection followed by sputum collection inside the lab and near to the lab $(26 \%$ and $18 \%$ respectively). Half of HFs used to disinfect the remaining sputum collection followed by burying it with other waste and bury it (40\% and $9 \%$ respectively).

\section{Personal protective equipment}

Only half of HFs $(51 \%, 40$ out of 79$)$ had mask available at HF. Among them, more than one third $(38 \%, 15$ out of 40$)$ had N95 or FPP2 mask. However, no HFs practice fit test for respirator before doing their regular work using masks. Half of health workers were found to have $(49 \%)$ used gloves during lab work, while one fifth $(27 \%)$ used gloves during sputum sample collection from suspected TB patients. Six out of every ten (61\%) HFs had apron available for health worker. Among them, health workers from three fifth of HFs $(77 \%$, 37 out of 48 ) were found to have used apron. Only $17 \% \mathrm{HFs}$ has provision to keep personal and lab apron separately. Only $3 \mathrm{HFs}(13 \%)$ were found to practice wearing special shoes in lab. Majority of microscopy centers (20 out of 23) were found to disinfectant or bury remaining sputum after sample collection.

\section{Environmental controls}

Among them, around half of the HFs (44\%, 35 out of 79 ) had cross ventilation. Specifically, among the microscopy centers, $(91 \%, 21$ out of 23$)$ had proper sunlight at lab. More than one third of microscopy centers $(26 \%, 6$ out of 23$)$ had exhaust fan in their lab. However, only 2 of them had exhaust fan properly placed to control direction of air. Majority of laboratory had wall (96\%, 22 out of 23) and floor $(96 \%, 22$ out of 23$)$ smooth to reduce the risk of TB transmission. Very few (4 out of 79) HFs had pick flow present at HFS to measure Air change per hour $(\mathrm{ACH})$. Only 3 of them were found to have used pick flow to measure $\mathrm{ACH}$ and had maintained the record. Similarly, only $3 \mathrm{HFs}$ had UVGI light, which was found installed by technical person. Only 10 $\mathrm{HFs}$ had biosafety cabinet available, of which only 6 were working. Three fifth $(75 \%, 59$ out of 79$)$ of them had disinfectant available. Majority of HFs had Phenol and Hypochlorite at their disposal for the purpose of disinfection. All HFswere found to have basin. Two fifth of the lab $(74 \%, 17$ of 23$)$ were found to prepare sputum slide on table, while rest of them prepared on slab.

\begin{tabular}{|c|c|}
\hline $\begin{array}{l}\text { TB Infection Control (TBIC) measures at } \\
\text { health facilities }\end{array}$ & $\begin{array}{l}\text { Number }(\%) \\
(\mathrm{n}=79)\end{array}$ \\
\hline \multicolumn{2}{|l|}{ Managerial measures } \\
\hline HFs having Infection prevention plan & $35(44 \%)$ \\
\hline $\begin{array}{l}\text { TB-IC included in Infection prevention plan } \\
(n=35)\end{array}$ & $24(69 \%)$ \\
\hline Budget allocated for TBIC $(n=24)$ & $12(50 \%)$ \\
\hline HFs has focal person for IC & $22(28 \%)$ \\
\hline HFs has IC committee & $9(11 \%)$ \\
\hline Previously IC assessment done in HFs & $20(25 \%)$ \\
\hline \multicolumn{2}{|l|}{ Administrative measures } \\
\hline Screening of TB patients in HFs & $70(89 \%)$ \\
\hline $\begin{array}{l}\text { Provision for separation of presumptive TB } \\
\text { patients }\end{array}$ & $24(30 \%)$ \\
\hline $\begin{array}{l}\text { Practice of separation of presumptive TB } \\
\text { patients }(n=24)\end{array}$ & $19(80 \%)$ \\
\hline Provision of mask for patients & $27(34 \%)$ \\
\hline Provision of tissue for patients & $15(19 \%)$ \\
\hline $\begin{array}{l}\text { Provision of dustbin to dispose used mask } \\
\text { and tissue }\end{array}$ & $56(71 \%)$ \\
\hline \multicolumn{2}{|l|}{ Personal protective measures } \\
\hline Apron available for HW & $48(61 \%)$ \\
\hline Apron used by HW & $37(77 \%)$ \\
\hline $\begin{array}{l}\text { Provision to keep personal clothes and lab } \\
\text { apron separately }\end{array}$ & $13(17 \%)$ \\
\hline $\begin{array}{l}\text { Provision to keep used and clean apron } \\
\text { separately }\end{array}$ & $18(23 \%)$ \\
\hline HW uses special shoes in lab $(n=23)$ & $3(13 \%)$ \\
\hline \multicolumn{2}{|l|}{ Environmental Control measures } \\
\hline Pick flow present at HFs & $4(5 \%)$ \\
\hline $\mathrm{ACH}$ measured in HFs $(n=4)$ & $3(75 \%)$ \\
\hline $\mathrm{ACH}$ flow recorded and maintained & $3(75 \%)$ \\
\hline 24-hour electricity available at HFs & $72(91 \%)$ \\
\hline Adequate water facility at HFs & $72(91 \%)$ \\
\hline \multicolumn{2}{|l|}{ Equipment for infection control } \\
\hline Autoclave available at HFs & $71(91 \%)$ \\
\hline Autoclave in working condition $(n=71)$ & $71(100 \%)$ \\
\hline $\begin{array}{l}\text { Records of time, pressure maintained } \\
(\mathrm{n}=71)\end{array}$ & $46(65 \%)$ \\
\hline Disinfectant in HFs & $59(75 \%)$ \\
\hline Availability of buckets for waste collection & $48(63 \%)$ \\
\hline
\end{tabular}




\section{DISCUSSION}

Less than half of HFs had infection prevention plan and only few of them had budgeted for TB IC. Dedicated focal person to implement and monitor IC activities are crucial; however only $28 \% \mathrm{HFs}$ had dedicated focal person to oversee infection control activities. A systematic review along with similar studies conducted in India, China and Nigeria have also underlined the need of administrative and managerial support for TB infection control measures. ${ }^{14,15,16,17} \mathrm{~A}$ proper infection plan, designated focal person and adequate budget allocation are inevitable for proper planning and implementation of infection control activities at facility level. Similarly, prompt identification and separation of people with TB symptoms (i.e. triage) is crucial. However, this study found very few health facilities have provision for the separation of presumptive TB patients and very few of them has practiced it at their HF. Evidences have shown that cough etiquette alone is a successful measure for TB infection control and have highlighted the need of Information, Education and Communication materials and mechanism at $\mathrm{HFs}{ }^{18}{ }^{1} \mathrm{n}$ this study, only $33 \% \mathrm{HFs}$ has provision of mask for TB patients. Less than half of health facilities do not have IEC materials available on HFs.

Only half of HFs had respirators available for health workers. Furthermore, only $15 \mathrm{HFs}$ has N95 or FPP2 mask. In line with other study, this study also highlights the needs of particulate respirators in HFs in order to have additional protection from risk of TB transmission. ${ }^{19}$ Likewise, only half of the HFs had cross ventilation. Moreover, only $3 \mathrm{HFs}$ had UVGI.Adequate ventilation and sufficient UVGI in health-care facilities is essential for preventing transmission of airborne infections and is strongly recommended for controlling spread of TB and respiratory infections. ${ }^{20}$

This study has couple of important limitations. First, this study couldn't cover all the facilities as determined by the sampling methodology due to budgetary and time constraints. It affected the generalize ability of this study. Similarly, private sector providing tuberculosis diagnosis and treatment services were not included in the sampling frame of the study. Expanding sampling frame beyond HFs under NTP could have brought additional evidences.

\section{CONCLUSION}

There is the risk of TB transmission at health facilities. Tuberculosis infection control measures at health facilities needs to be assessed and strengthened specifically the administrative, managerial, environmental and personal protective measures to minimize the risk of tuberculosis transmission. Different divisions/centers under Ministry of Health and Population (like National Health Training Center, National Health Education Information and Communication Center, Logistics Management Division, National Center for AIDS and STD Control, Management Division), National Tuberculosis Program, province and local level administrative bodies and health facilities should collaborate to strengthen the efforts and place TB infection control intervention among priority interventions.

\section{ACKNOWLDEGEMENT}

We would like to remember all the Provincial TB Coordinators (Barsha Thapa, Bimal Subedi, Sailesh Bhujel, Bharati KC, Diwas Acharya, Rajesh Sah) for their support throughout the study period. Similarly, we express our gratitude towards all the health facilities who participated in this study, and enumerators for their effort to complete the field level activities on time.

\section{CONFLICT OF INTEREST}

None

\section{REFERENCES}

1. WHO. Tuberculosis [Internet]. Available from:http:// www.who.int/mediacentre/factsheets/fs104/en/ [cited 2018 Jan 10].

2. Global tuberculosis report 2017. Geneva: World Health Organization; 2017. Available from:https:// www.who.int/tb/publications/2017/en/

3. UNAIDS. Tuberculosis and HIV [Internet]. Available from: htttp://www.unaids.org/en/resources/ infographics/eliminating-tb-deaths-HIV/[cited 2018 Jan 11].

4. Ormerod LP. Multidrug-resistant tuberculosis (MDR-TB): epidemiology, prevention and treatment. Br Med Bull. 2005 Jan 1;73-74(1):1724. 
5. Annual Report 2015/16. Kathmandu: Department of Health Services; 2016. Available from: http:// dohs.gov.np/

6. Tuberculosisprofile Nepal 2016. Geneva: WHO; 2017 Available from: https://www.who.int/tb/ country/data/profiles/en/

7. Annual report 2072/73 (2016) National Tuberculosis Program Nepal. Kathmandu: National Tuberculosis Center; 2017 March. Available from:http://nepalntp. gov.np/pub_cat/reports/

8. Buregyeya $E$, Nuwaha F, Verver S, Criel B, et al. Implementation of tuberculosis infection control in health facilities in Mukono and Wakiso districts, Uganda. BMC Infect Dis. 2013 Aug 1;13:360. Available from: https://www.ncbi.nlm.nih.gov/pmc/ articles/PMC3735480/

9. Centers for Disease Control and Prevention. Infection Control in Health Care Settings. [Internet]. Available from: https://www.cdc.gov/tb/topic/ infectioncontrol/default.htm[cited 2018 Jan 11].

10. WHO Policy on TB Infection Control in Health-Care Facilities, Congregate Settings and Households [Internet]. Geneva: World Health Organization; 2009 [cited 2018 Jan 11]. (WHO Guidelines Approved by the Guidelines Review Committee). Available from: http://www.ncbi.nlm.nih.gov/books/ NBK179249/

11. Implementing the WHO Policy on TB Infection Control in Health-Care Facilities, Congregate Settings and Households. Geneva: WHO; 2009. (100 p.) Available from: http://apps.who.int/iris/ bitstream/handle/10665/44148/9789241598323 eng.pdf;jsessionid=2D5DD0913C 17 ADE79F4272 05673F7030? sequence $=1$

12. Sampling Manual for Facility Surveys for Population, Maternal Health, Child Health and STD Programs in Developing Countries. MEASURE Evaluation Manual Series, No. 3. MEASURE Evaluation. Carolina Population Center, University of North Carolina at Chapel Hill. July 2001. Available from: https://www.measureevaluation.org/resources/ publications/ms-01-03/at_download/document.

13. Ministry of Health, Nepal; New ERA; and ICF. 2017. Nepal Demographic and Health Survey 2016.Kathmandu, Nepal: Ministry of Health, Nepal. Available from: https://www.dhsprogram.com/ pubs/pdf/fr336/fr336. pdf
14. Sachdeva KS, Deshmukh RD, Seguy NS, Nair SA, et al. Tuberculosis infection control measures at health care facilities offering HIV and tuberculosis services in India: A baseline assessment. Indian J Tuberc. (2018). Available from: https:// www.sciencedirect.com/science/article/pii/ S0019570717303736

15. Kuyinu YA, Mohammed AS, Adeyeye OO, Odugbemi BA, et al. Tuberculosis infection control measures in health care facilities offering TB services in Ikeja local government area, Lagos, South West, Nigeria. BMC Infect Dis. 2016;16:126. Available from: https://www.ncbi.nlm.nih.gov/pmc/ articles/PMC4791906/

16. Lin $Y$, Harries AD. Tuberculosis infection control measures in diabetes clinics in China: a rapid assessment of 10 hospitals. Trop Med Int Health. 2015;20(9):1196-1200. Available from: https:// www.ncbi.nlm.nih.gov/pubmed/25959044

17. Godfrey C, Tauscher G, Hunsberger S, et al. A survey of tuberculosis infection control practices at the NIH/NIAID/DAIDS supported clinical trial sites in low and middle-income countries. BMC Infect Dis. 2016; 16:269. Available from: https://www. ncbi.nlm.nih.gov/pubmed/27287374

18. Lai KK, Fontecchio SA, Kelley AL, Melvin ZS. Knowledge of the transmission of tuberculosis and infection control measures for tuberculosis among healthcare workers. Infect Control Hosp Epidemiol. 1996;17:168-170. Available from:https://www.ncbi. nlm.nih.gov/pubmed/8708355

19. Malik M, Parmar KS, Kiran Rade S, et al. Airborne infection control in India: baseline assessment of health facilities. Indian J Tuberc. 2015;62(October (4)):211-217. Available from: https://www.ncbi.nlm. nih.gov/pubmed/26970461

20. Escombe AR, Moore DAJ, Gilman RH, et al. Upperroom ultraviolet light and negative air ionization to prevent tuberculosis transmission. PLoS Med. 2009;6(3):e1000043. Available from: https:// journals. plos.org/plosmedicine/article?id=10.1371/ journal.pmed. 1000043 